\title{
A Longitudinal Study of the Reciprocal Nature of Risk Behaviors and Cognitions in Adolescents: What You Do Shapes What You Think, and Vice Versa
}

\author{
Meg Gerrard, Frederick X. Gibbons, Alida C. Benthin, and Robert M. Hessling \\ Iowa State University
}

\begin{abstract}
Adolescents' reckless driving, drinking, and smoking, along with their cognitions about these behaviors, were assessed in a 3-year longitudinal design. Consistent with most models of health behavior, the results indicated that health cognitions predict risk behavior. In addition, the current data demonstrate that increases in risk behavior are accompanied by increases in perceptions of vulnerability and prevalence and by decreases in the influence of concerns about health and safety. Furthermore, the changes in prevalence estimates and concern about health and safety predicted subsequent risk behavior. These results demonstrate reciprocity between risk behaviors and related cognitions and suggest that adolescents are aware of the risks associated with their behavior but modify their thinking about these risks in ways that facilitate continued participation in the behaviors.
\end{abstract}

Key words: adolescent, risk behavior, health cognitions

Most health behavior models suggest that cognitions, such as perceptions of vulnerability to harm and perceptions of the costs and benefits of adopting precautions, guide decisions to engage in both risk and preventive behaviors. In fact, there is a wealth of research documenting the influence of such cognitions on health risk behaviors (cf. Harrison, Mullen, \& Green, 1992; Janz \& Becker, 1984). What is surprising, however, is that there has been little research on the reciprocal nature of the relation between health cognitions and health behavior. The primary purpose of the current study was to examine the hypothesis that, in addition to health cognitions influencing participation in risk behavior, engaging in risk behaviors influences health cognitions.

\section{Impact of Health-Related Cognitions on Risk Behavior}

Implementation of a wide variety of health educational programs over the last two decades is responsible for increases in awareness of the risks associated with smoking, drinking, driving, and unprotected sex (Eiser, Eiser, \& Lang, 1989; Finn \& Bragg, 1986; Finn \& Brown, 1981; Gerrard, Gibbons, \& Warner, 1991; Gerrard \& Luus, 1995; Leventhal, Glynn, \& Fleming, 1987). Unfortunately, however, these increases in awareness about health risks and personal vulnerability have

Meg Gerrard, Frederick X. Gibbons, Alida C. Benthin, and Robert M. Hessling, Department of Psychology, lowa State University.

This research was supported by National Institute of Mental Health Grant 1 P50 MH48165-01, National Institute on Drug Abuse Grant DA07534A, and National Institute on Alcohol Abuse and Alcoholism Grant AA10208. We would like to thank Hart Blanton and Susan Cross for their comments on an earlier version of this article.

Correspondence concerning this article should be addressed to Meg Gerrard, Department of Psychology, Iowa State University, W112 Lagomarcino Hall, Ames, lowa 50011-3180. Electronic mail may be sent via Internet to mgerrard@iastate.edu. not been accompanied by corresponding declines in risk behaviors (Janus \& Janus, 1993; Public Health Service, 1993; Roscoe \& Kruger, 1990; Rotheram-Borres \& Koopman, 1991). In fact, the prevalence of many risk behaviors among adolescents may actually be increasing (Centers for Disease Control, 1992, 1993). Thus, it appears that adolescents are aware of the risks, but this awareness does not inhibit them from engaging in the behaviors. A secondary purpose of the current study, then, was to address the question of how adolescents can continue to engage in behaviors that they apparently know are putting them at risk.

\section{The Reciprocal Relation Between Risk Behaviors and Cognitions}

The idea that health behaviors affect health-relevant cognitions is not new. In fact, almost 40 years ago Festinger (1957) discussed the predicament of a hypothetical smoker who had recently learned that smoking was harmful. He proposed that individuals who continued smoking could choose between two alternative ways of dealing with this information: They could deny the relation between their behavior and potential negative consequences, or they could engage in various cognitive strategies that would enable them to continue smoking (e.g., deciding that the benefits of smoking outweigh the dangers or that the risk is negligible in comparison with that of other activities; cf. Lawton \& Goldman, 1961; Pervin \& Yatko, 1965 ). Since this early work, however, little attention has been paid to the impact that engaging in risk behavior has on health-related cognitions. Given the prominence of perceptions of vulnerability in models of health behavior, it is particularly surprising that there is a paucity of research on the impact of risk behavior on this specific cognition.

Until recently, thinking about the effects of risk taking on perceptions of vulnerability has been dominated by a long 
tradition in clinical research suggesting that people deny or minimize their vulnerability to alleviate anxiety over the potential negative consequences of their behavior. In an early statement of this principle, Janis (1958) hypothesized that as individuals approach a risk, the proximity of the threat elicits denial. This premise suggests, then, that one reason that people continue to engage in behaviors that they know are risky is that they deny the possibility of negative consequences.

We suggest that educational programs implemented over the last two decades have made it exceedingly difficult for people to engage in what Weisman (1972) refers to as "first-order" denial of health risks (e.g., refusing to believe that smoking increases the likelihood of cancer). In spite of evidence that people tend to minimize the seriousness of potential health risks (Croyle, 1990; Croyle \& Sande, 1988; Ditto, Jemmott, \& Darley, 1988), a number of recent studies have suggested that perceptions of vulnerability reflect awareness of risk rather than denial (cf. Weinstein \& Nicolich, 1993). For example, a cross-sectional examination of 14 different risk behaviors indicated that adolescents who participated most in a risk behavior reported feeling the most vulnerability to the negative consequences associated with that behavior (Cohn, Macfarlane, Yanez, \& Imai, 1995). Similarly, college students perceptions of vulnerability have been shown to correlate with their actual probability of experiencing a variety of health hazards (Rothman, Klein, \& Weinstein, in press). In addition, a meta-analysis of studies of the relation between sexual risk behavior and perceptions of vulnerability to HIV indicated that people who engage in more sexual risk behaviors have higher estimates of their likelihood of contracting HIV than do people who engage in fewer risk behaviors (Gerrard, Gibbons, \& Bushman, 1996). Thus, it appears that people typically do not cope with the apparent contradiction between their behavior and their awareness of its potential negative consequences by engaging in first-order denial. We propose that, instead, adolescents who engage in risk behaviors deal with this contradiction by altering or manipulating their cognitions about the behaviors in two specific ways. First, they convince themselves that many others are also taking the same risks, and, second, they avoid thinking about the dangers associated with their behavior.

\section{Cognitive Shifts Associated With Increased Risk Behavior}

\section{Prevalence Estimates}

Snyder and Wicklund (1981) theorized that when people do something they think is undesirable, they normalize their actions by engaging in a process of "claiming consensus," thus making the behavior seem more benign. A number of studies have demonstrated this type of "false consensus" effect (Ross, Greene, \& House, 1977) in relation to health risk behaviors: The frequency of individuals' participation in specific risk behaviors has been shown to be associated with their estimates of the prevalence of smoking, drug use, and drinking (Gibbons, Helweg-Larsen, \& Gerrard, 1995; Kandel, 1980; Leventhal et al., 1987; Sherman, Presson, Chassin, Corty, \& Olshansky, 1983; Sussman et al., 1988). Using a longitudinal design,
Collins et al. (1987) demonstrated that adolescents' prevalence estimates predicted onset of and increases in smoking at a 16-month follow-up. In addition, a study by Marks, Graham, and Hansen (1992) demonstrated that adolescents' alcohol consumption is positively associated with their concurrent estimates of the number of their peers who drink. These prevalence estimates, in turn, are positively associated with subsequent alcohol consumption. These studies did not, however, examine adjustments in prevalence estimates associated with increased drinking.

\section{Disregarding Consequences}

Another (and perhaps less intuitive) cognitive adjustment that people can make when dealing with the knowledge that their behavior has increased their vulnerability to negative consequences has to do with the extent to which they consider this information when making decisions. Specifically, one option is to disregard the potential negative consequences by decreasing the influence such thoughts have on one's behavior. Although first-order denial of risk is uncommon, people can engage in a "denial-like process" (Lazarus, 1983) of avoiding thinking about the danger; in other words, the fear associated with awareness of the danger inherent in risk behavior can be brought under control by avoiding thinking about it. According to Lazarus, "A terminal patient may know full well that he or she is dying, but prefer not to think or talk about it. This is not denial, but avoidance" (p. 10).

\section{Impact on Subsequent Risk Behavior}

Some people who initiate or increase risk behavior undoubtedly respond to their awareness of increased risk by decreasing or even ceasing the risk behavior. Others, however-and we suspect that many adolescents fall into this categoryrecognize their vulnerability but continue to engage in the behavior. We suggest that these two cognitive shifts, normalizing the behavior and decreasing the influence of concerns about negative consequences, result in continuation of, or even an increase in, the behavior.

\section{Current Study}

The current study examined the reciprocal relation between health cognitions and adolescents' participation in three health risk behaviors: reckless driving, drinking, and smoking. On the basis of previous research, four hypotheses were generated. First, we hypothesized that adolescents' estimates of the prevalence of specific risk behaviors and their concerns about health and safety are predictive of their subsequent risk behavior. Second, when adolescents initiate or increase specific risk behaviors, they increase their perceptions of vulnerability to the negative consequences associated with those behaviors (cf. Gerrard, Gibbons, Warner, \& Smith, 1993; Weinstein \& Nicolich, 1993). Third, as adolescents initiate or increase a specific risk behavior, they will increase their estimates of the prevalence of that behavior among their friends and report a decline in the extent to which the potential negative consequences of that behavior are likely to influence 
their thinking. (The opposite of each of these effects would be expected for adolescents who decrease their risk behavior; however, the relatively small number of adolescents decreasing risk behaviors makes it difficult to test these effects.) Fourth, we hypothesized that these increases in prevalence estimates and decreases in consideration of negative consequences are associated with subsequent increases in risk behavior. ${ }^{3}$

\section{Method}

\section{Participants}

Participants in this study were 231 male and 246 female adolescents who completed the first two waves of data collection (Time 1 [T1] and Time 2 [T2]) in an ongoing longitudinal study of health risk behaviors conducted in rural areas of Iowa (T1 to $\mathrm{T} 2$ retention rate $=95 \%$; Gibbons \& Gerrard, 1995; Gibbons, Gerrard, \& Boney-McCoy, 1995; Gibbons, Helweg-Larsen, \& Gerrard, 1995). The 220 boys and 233 girls who participated in a third wave of data collection (Time 3 [T3]) were included in follow-up analyses of subsequent risk behavior (T2 to T3 retention rate $=93 \%$ ). Half of the adolescents were in the 8th grade, and half were in the 10th grade, at $\mathrm{T} 1$; their mean age at that time was 14. (It is legal for 14-year-olds to drive in rural lowa.)

\section{Procedure}

The adolescents' families' participation in the study was solicited via mailings to the parents of all 8th and 10th graders in chosen rural public schools throughout the state. To be included target adolescents had to have a sibling within 2 years of their age, and the sibling and custodial parent(s) had to be willing to participate in the study. Of the families that met these criteria, $73 \%$ agreed to participate.

Questionnaires were administered in the families' homes by a trained interviewer at each time period, approximately 1 year apart. After presenting instructions and obtaining informed consent, the interviewer asked the adolescents (and other family members) to complete the questionnaire in private. Anonymity was stressed, and all family members were reminded several times that they were not to discuss each other's responses at any time. Each family was paid $\$ 50$ for their participation at $\mathrm{T} 1$ and $\mathrm{T} 2$ and $\$ 55$ at $\mathrm{T} 3$. The data collected from family members other than the target adolescent were intended for another study.

\section{Measures}

Risk behaviors. Reckless driving was assessed through the following item: "Sometimes both adults and teenagers drive carelessly or recklessly (too fast or in a dangerous way). How many times in the last 3 months have you driven recklessly?" The options were never (1), once or twice (2), a few times. (3), more than a few times (4), and regularly (5). The drinking question was "How many times in the last 3 months have you had a whole drink of alcohol (for example, a bottle of beer, a glass of wine, or a whole mixed drink)?" The response options for this question were never (1), once or twice (2), a few times (3), more than a few times (up to once a week) (4), and regularly (at least two times a week) (5). Smoking was assessed with the question "How often do you smoke now?' Response options were not at all (1), a few times every month (2), several times a week (3), and every day (4).

In an effort to check the validity of the adolescents' self-reports of their behavior, we also asked parents to estimate their child's participation in these behaviors (cf. Stacy, Widaman, Hays, \& DiMatteo, 1985). Although the parents consistently underestimated relative to their son's or daughter's self-report, the correlations between both parents' estimates and the adolescents' self-reports of all three risk behaviors were significant and ranged from .24 to $.68(p \mathrm{~s}<.01)$. These correlations, together with the emphasis placed on accuracy and anonymity in the instructions given to all participants, suggest that the adolescents' reports were reasonably valid indicators of their behaviors. Previous research has also suggested that these types of self-reports among adolescents have reasonable validity (see Brown, Clasen, \& Eicher, 1986).

Perceived vulnerability. Perceptions of vulnerability were assessed via two questions for each risk behavior. The questions for accident risk were "How likely is it that your driving will cause a car or motorcycle accident that injures someone at some time in the future?" ( $1=$ no chance, $7=$ definitely will happen $)$ and "Compared to others your age, how likely is it that your driving will cause a car (or motorcycle) accident that injures someone at some time in the future?" ( 1 = much less likely than others, $7=$ much more likely than others). The drinking risk questions were "How likely is it that you will have a drinking problem at some time in the future?" and "Compared to others your age, how likely is it that you will have a drinking problem at some time in the future?" For smoking risk, the questions were "How likely is it that you will have a smoking-related illness (e.g., lung cancer) at some time in the future?" and "Compared to others your age, how likely is it that you will have a smoking-related illness (e.g., lung cancer) at some time in the future?" (Responses to the drinking and smoking risk questions were made on the scales just described). T1 alphas on the perceptions of vulnerability questions for specific risks ranged from .68 to $.76 ; \mathrm{T} 2$ alphas ranged from .65 to .81 .

Avoidance of thoughts about health and safety. Avoidance of thoughts about health and safety were assessed via one question for each risk behavior (e.g., "How likely is concern for your health and safety to influence your drinking behavior?"). Participants responded to these questions on a scale ranging from not at all (1) to very much (7).

Estimated prevalence. The adolescents' estimates of the prevalence of reckless driving, drinking, and smoking were each assessed with two questions about their friends' and peers' behaviors (e.g., "How many of your friends smoke?" and "How many people your age do you think smoke?"). Responses to these questions were recorded as percentages. Alphas for these measures ranged from .63 to .81 .

\section{Results}

\section{Oveniew}

The results are organized into four sections. The first describes the adolescents' risk behaviors, changes in those behaviors over time, and the correlations between the three risk behaviors. The second reports the effect of health and safety concerns and perceived prevalence (T1) on changes in risk behavior (from $\mathrm{T} 1$ to $\mathrm{T} 2$ ). The third includes analyses related to the hypothesis that these cognitions change as a function of change in risk behavior (from $\mathrm{T} 1$ to $\mathrm{T} 2$ ). The fourth set of analyses tested the hypothesis that subsequent increases in risk behaviors (from T2 to T3) are associated with adoles-

\footnotetext{
${ }^{1}$ Given Weinstein, Rothman, and Nicolich's (1995) recent suggestion that correlations between perceptions of vulnerability and future risk behavior are spurious (and positive), we were reluctant to hypothesize about this relation. Although elaboration of this issue is beyond the scope of this article, the current data support their argument. More specifically, when $\mathrm{T} 1$ perceptions of vulnerability were used to predict T2 risk behaviors (controlling for T1 risk behavior), the correlations were $.08(p<.05)$ for drinking and .07 $(p<.10)$ for reckless driving (the correlation for smoking was $.01, n s$ ).
} 
Table 1

Percentage of Participants Reporting Risk Behavior and Behavior Change

\begin{tabular}{|c|c|c|c|c|c|c|}
\hline Time & \multicolumn{2}{|c|}{ Reckless driving } & \multicolumn{2}{|c|}{ Drinking $^{a}$} & \multicolumn{2}{|c|}{ Smoking $b$} \\
\hline $\begin{array}{l}\text { T1 } \\
\text { T2 } \\
\text { T3 }\end{array}$ & & & & & & \\
\hline \multicolumn{7}{|c|}{$\mathrm{T} 1-\mathrm{T} 2$ change category } \\
\hline $\begin{array}{l}\text { No risk } \\
\text { T1 } \\
\text { T2 }\end{array}$ & $\begin{array}{l}\% \\
34\end{array}$ & $\begin{array}{l}M \\
1.0 \\
1.0\end{array}$ & $\begin{array}{l}\% \\
54\end{array}$ & $\begin{array}{l}M \\
1.0 \\
1.0\end{array}$ & $\begin{array}{l}\% \\
90\end{array}$ & $\begin{array}{l}M \\
1.0 \\
1.0\end{array}$ \\
\hline $\begin{array}{c}\text { Decrease } \\
\text { T1 } \\
\mathrm{T} 2\end{array}$ & 11 & $\begin{array}{l}3.0 \\
1.7\end{array}$ & 8 & $\begin{array}{l}3.0 \\
1.9\end{array}$ & 2 & $\begin{array}{l}2.6 \\
1.1\end{array}$ \\
\hline $\begin{array}{c}\text { Increase } \\
\text { T1 } \\
\text { T2 }\end{array}$ & 43 & $\begin{array}{l}1.5 \\
3.0\end{array}$ & 27 & $\begin{array}{l}1.5 \\
3.0\end{array}$ & 6 & $\begin{array}{l}1.3 \\
3.0\end{array}$ \\
\hline $\begin{array}{c}\text { Same risk } \\
\text { T1 } \\
\text { T2 }\end{array}$ & 11 & $\begin{array}{l}2.4 \\
2.4\end{array}$ & 11 & $\begin{array}{l}2.8 \\
2.8\end{array}$ & 2 & $\begin{array}{l}2.5 \\
2.5\end{array}$ \\
\hline
\end{tabular}

Note. The scales for drinking and reckless driving were as follows: $1=$ never, 2 ance or nice, $3=a$ few times, $4=$ more than a few times, and $5=$ regularly. The scale for smoking was as follows: $1=$ not at all, $2=a$ few times $a$ month, $3=$ several times a week, and $4=$ every day. Sample sizes were 476 at Time 1 (T1), 476 at Time 2 (T2), and 453 at Time 3 (T3). See text for details on behavior change categories.

aPercentage who reported engaging in the behavior more than once or twice during the last 3 months. bercentage reporting currently smoking at least a few times a month.

cents' altered cognitions about their health and safety and the prevalence of the risk behaviors.

\section{Behavior and Behavior Change}

Participants were divided into the following four behavior change categories based on their reports of participation in each of the four risk behaviors: no risk, increasing risk, decreasing risk, and same risk. Adolescents in the no risk category reported minimal risk behaviors at both $\mathrm{T} 1$ and $\mathrm{T} 2$ (i.e., they drove recklessly or drank alcohol no more than once or twice, or they did not smoke). Adolescents in the increasing risk category reported at least a 1-point increase between T1 and $\mathrm{T} 2$ on the scales measuring the frequency of the specific behavior. For example, adolescents who reported drinking once or twice at $\mathrm{T} 1$ and reported drinking a few times at $\mathrm{T} 2$ were classified as increasers. Similarly, those in the decreasing risk category reported at least a 1-point decrease in their frequency between $\mathrm{T} 1$ and $\mathrm{T} 2$. Those in the same risk category reported engaging in the behavior at least "a few times" at $T 1$ and the same amount at $\mathrm{T} 2$. Table 1 presents the percentage of adolescents who reported engaging in the behaviors at $\mathrm{T} 1, \mathrm{~T} 2$, and $\mathrm{T} 3$, as well as the percentage in each $\mathrm{T} 1-\mathrm{T} 2$ behavior change category.

The smoking and drinking behavior reported by this sample was similar to national norms for this age group (U.S. Department of Health and Human Services, 1990). Although we are not aware of national data on self-reported reckless driving, we assumed that the prevalence of this risk behavior was higher in this sample than elsewhere because of the lower than average legal driving age in rural Iowa. Eighty percent of the adolescents reported driving at $\mathrm{T} 1,95 \%$ reported driving at $\mathrm{T} 2$, and $98 \%$ reported driving at $\mathrm{T} 3$.

As expected, there were significant increases in the proportion of adolescents engaging in all three risk behaviors from $\mathrm{T} 1$ to $\mathrm{T} 2$ and from $\mathrm{T} 2$ to $\mathrm{T} 3$ (all $p$ s $<.01$ ). As can be seen in Table 2 , the risk behaviors were moderately correlated with each other and had moderate to high stability over time.

\section{Changes in Risk Behavior as a Function of Health Cognitions}

To assess the effect of $\mathrm{T} 1$ cognitions on changes in behavior between $\mathrm{T} 1$ and $\mathrm{T} 2$, we conducted two hierarchical regression analyses predicting $\mathrm{T} 2$ behavior from $\mathrm{T} 1$ risk behavior and $\mathrm{T} 1$ cognitions (prevalence of risk behaviors among peers, and ratings of the influence of concerns about health and safety) for each of the three risk behaviors (reckless driving, drinking, and smoking). In each of these six analyses, T1 behavior was entered in Step 1 (thereby controlling for T1 behavior), followed by $\mathrm{T} 1$ cognition in Step 2 . For example, in the first analysis, we predicted $\mathrm{T} 2$ reckless driving from the adolescents' estimates of the prevalence of reckless driving, controlling for $\mathrm{T} 1$ reckless driving. Thus, these analyses, in effect, predicted $\mathrm{T} 1$ to $\mathrm{T} 2$ changes in behavior from $\mathrm{T} 1$ cognitions about the behavior.

As can be seen in Table 3, the adolescents' reckless driving, drinking, and smoking at T1 were significant predictors of these behaviors at $\mathrm{T} 2(\beta \mathrm{s}=.49, .64$, and .49 , respectively, all $p s<.001)$. In addition, estimates of the prevalence of these behaviors, and the influence of concerns about health and safety, predicted all three risk behaviors at $\mathrm{T} 2$ after the influence of $\mathrm{T} 1$ behavior had been controlled. Thus, as expected, these cognitions at $\mathrm{T} 1$ predicted changes in behavior between $\mathrm{T} 1$ and $\mathrm{T} 2$.

\section{Changes in Cognitions as a Function of Behavior Change}

To assess the effect of T1-T2 behavior change on T1-T2 changes in risk-relevant cognitions, we conducted a set of three hierarchical regression analyses predicting $T 2$ cognitions (perceptions of vulnerability, prevalence of risk behaviors among peers, and ratings of the influence of concerns about health and safety) for each of the three risk behaviors. In each of these nine analyses, $T 1$ behavior and $T 1$ cognition were entered in Step 1, followed by $\mathrm{T} 2$ behavior in Step 2 (therefore,

Table 2

Correlations Between Risk Behaviors

\begin{tabular}{llll}
\hline \multicolumn{1}{c}{ Behavior } & 1 & 2 & 3 \\
\hline 1. Reckless driving & $.49^{* *}$ & $.35^{* *}$ & $.18^{* *}$ \\
2. Drinking & $.43^{* *}$ & $.64^{* *}$ & $.39^{* *}$ \\
3. Smoking & $.28^{* *}$ & $.36^{* *}$ & $.51^{* *}$ \\
\hline
\end{tabular}

Note. Correlations between Time 1 (T1) behaviors are above the diagonal, and correlations between Time 2 (T2) behaviors are below the diagonal. Correlations on the diagonal are correlations between $\mathrm{T} 1$ and $\mathrm{T} 2$ assessments of each behavior. $N \mathrm{~s}=471$ to 476 .

${ }^{* *} p<.01$. 
both $\mathrm{T} 1$ behavior and $\mathrm{T} 1$ cognitions were controlled). Thus, these analyses predicted changes in cognitions from changes in behavior.

Reckless driving. As can be seen in Tables 4 and 5, T1 to T2 changes in reckless driving behavior predicted changes in perceptions of vulnerability to the negative consequences of reckless driving ( $\beta=.28, p<.01$ ), in estimates of the prevalence of reckless driving $(\beta=.27, p<.01)$, and in the influence of health and safety concerns $(\beta=-.23, p<.01)$. The pattern of these regressions indicated that increases in reckless driving between $\mathrm{T} 1$ and $\mathrm{T} 2$ were accompanied by increased perceptions of risk, increased prevalence estimates, and decreases in reported influence of concerns about health and safety.

In an effort to examine potentially differential patterns of cognitive changes in adolescents whose risk behavior increased, decreased, and remained stable, we also conducted a series of $2 \times 4$ (Time $\times$ Behavior Change Category) repeated measures analyses of variance (ANOVAs) on the adolescents' cognitions. These analyses included a separate ANOVA for each cognition. The Time $\times$ Behavior Change Category interactions were significant for all three driving-related cognitions: influence of health and safety concerns, $F(3,369)=4.45$, $p<.01$; perceptions of vulnerability, $F(3,371)=5.34, p<$ .001 ; and prevalence estimates, $F(3,328)=8.16, p<.001 .^{2}$ The pattern of these interactions was as expected in that simple effects analyses (paired $t$-test repeated measures analyses of the differences in cognitions from $\mathrm{T} 1$ to $\mathrm{T} 2$ ) indicated that the group of primary interest, the increasers, increased their perceptions of their personal risk as well as their estimates of the prevalence of reckless driving among their peers but reported reduced influence of concerns about health and safety (all $p$ s $<.01$; see Tables 4 and 5). In contrast, the decreasers showed a significant increase in reported influence of health and safety concerns $(p<.01)$ and a marginally significant decrease in perceptions of risk $(p<.10)$, and they were the only group that showed a tendency to decrease

Table 3

Time 2 Risk Behaviors as a Function of Time 1 (TI) Cognitions

\begin{tabular}{|c|c|c|c|}
\hline Variable & $\begin{array}{c}\text { Reckless } \\
\text { driving }\end{array}$ & Drinking & Smoking \\
\hline \multicolumn{4}{|c|}{ Prevalence estimates } \\
\hline \multirow{2}{*}{$\begin{array}{c}\text { T1 behavior (Step } 1 ; \beta) \\
\text { T1 prevalence estimates } \\
\text { (Step } 2 ; \beta)\end{array}$} & $.49^{* * *}$ & $.64^{* * *}$ & $.49^{* * *}$ \\
\hline & $.16^{* * *}$ & $.11^{* *}$ & $.11^{* *}$ \\
\hline $\begin{array}{l}\text { Overall } F \\
R^{2}\end{array}$ & $\begin{array}{c}86.00^{* * *} \\
27\end{array}$ & $\begin{array}{c}173.17^{* * *} \\
42\end{array}$ & $\begin{array}{c}86.40^{* * * *} \\
27\end{array}$ \\
\hline$d f$ & 2,465 & 2,469 & 2,462 \\
\hline
\end{tabular}

Health and safety concerns

\begin{tabular}{lccc}
$\begin{array}{l}\text { T1 behavior (Step 1; } \beta \text { ) } \\
\text { T1 influence of health and } \\
\text { safety concerns } \\
\quad \text { (Step 2; } \beta \text { ) }\end{array}$ & $.49^{* * *}$ & $.64^{* * *}$ & $.49^{* * *}$ \\
& $-.17^{* * *}$ & $-.11^{* *}$ & $-.09^{*}$ \\
Overall $F$ & $61.13^{* * *}$ & $120.37^{* * *}$ & $60.23^{* * *}$ \\
$R^{2}$ & .28 & .44 & .28 \\
$d f \quad$ & 2,471 & 2,465 & 2,472 \\
\hline${ }^{*} p<.05 .{ }^{* *} p<.01 . \quad{ }^{* * *} p<.001$. & &
\end{tabular}

Table 4

Time 2 (T2) Reckless Driving Cognitions as a Function of $T 2$ Reckless Driving

\begin{tabular}{|c|c|c|c|}
\hline \multirow[b]{2}{*}{ Variable } & \multicolumn{3}{|c|}{ Driving-related cognition } \\
\hline & $\begin{array}{c}\text { Risk } \\
\text { perception }\end{array}$ & $\begin{array}{l}\text { Estimated } \\
\text { prevalence }\end{array}$ & $\begin{array}{c}\text { Influence of } \\
\text { health and safety } \\
\text { concerns }\end{array}$ \\
\hline $\begin{array}{l}\text { T1 driving-related cog- } \\
\text { nition (Step } 1 ; \beta \text { ) } \\
\text { T1 reckless driving }\end{array}$ & $.38^{* *}$ & $.37^{* *}$ & $.50^{* *}$ \\
\hline $\begin{array}{c}\text { (Step } 1 ; \beta) \\
\text { T2 reckless driving }\end{array}$ & -.01 & -.01 & .05 \\
\hline$(\operatorname{Step} 2 ; \beta)$ & $.28^{* *}$ & $.27^{* *}$ & $-.23^{* *}$ \\
\hline $\begin{array}{l}\text { Overall } F \\
R^{2} \\
d f\end{array}$ & $\begin{array}{c}55.01^{* *} \\
.26 \\
3,470\end{array}$ & $\begin{array}{l}54.21^{* *} \\
.26 \\
3.464\end{array}$ & $\begin{array}{c}84.18^{* *} \\
.35 \\
3.464\end{array}$ \\
\hline
\end{tabular}

Note. $\quad$ T1 $=$ Time 1.

$*^{*} p<.01$.

(although not significantly) their estimates of the prevalence of reckless driving, in spite of the significant increase in actual reckless driving among their peers (see Table 1). All other groups recognized the increase in prevalence of this risk behavior $(p s<.05)$. It should also be noted that, with the exception of the no risk group, all adolescents clearly overestimated the prevalence of reckless driving among their peers (cf. Gibbons, Helweg-Larsen, \& Gerrard, 1995; Goethals, Messick, \& Allison, 1991; Ross et al., 1977; Suls, Wan, \& Sanders, 1988).

Drinking. The regression analyses revealed that $\mathrm{T} 1$ to $\mathrm{T} 2$ changes in drinking were accompanied by changes in cognitions relevant to drinking. Specifically, increases in drinking were also associated with increases in risk perception $(\beta=.41$, $p<.01)$, increases in prevalence estimates $(\beta=.23, p<.01)$, and decreases in the influence of health and safety concerns $(\beta=-.29, p<.01$; see Tables 6 and 7$)$.

As was the case with the change category analyses for reckless driving, the Time $\times$ Behavior Change Category interactions were significant for all three drinking cognitions: perceptions of vulnerability, $F(3,468)=12.52, p<.001$; cstimated prevalence, $F(3,467)=11.84, p<.001$; and influence of health and safety concerns, $F(3,464)=4.57, p<$ .01 . The pattern of changes among increasers followed predictions; members of this group increased their perceived personal risk and prevalence estimates and reported reduced influence of concerns about health and safety (all $p \mathrm{~s}<.01$ ). In contrast, decreasers significantly lowered their perceptions of vulnerability $(p<.01)$ and reported no change in influence of health and safety concerns.

All groups showed an awareness that the level of drinking among their peers and friends had risen from $\mathrm{T} 1$ to $\mathrm{T} 2, F(1$, $467)=98.56, p<.001$. This main effect was qualified by a significant Time $\times$ Behavior Change Category interaction, such that the largest increase in prevalence estimates occurred

\footnotetext{
${ }^{2}$ Initially, each of these analyses included gender as a third factor. Only 1 of the 27 interactions involving gender was significant, however, and that interaction was not meaningful. Thus, the analyses reported here do not include gender.
} 
Table 5

Time 1 (T1) and Time 2 (T2) Reckless Driving Cognitions as a Function of Change Category

\begin{tabular}{lcccc}
\hline \multicolumn{1}{c}{ Cognition } & \multicolumn{4}{c}{ Change category } \\
\cline { 2 - 5 } & $\begin{array}{c}\text { No risk } \\
(n=129)\end{array}$ & $\begin{array}{c}\text { Increase } \\
(n=162)\end{array}$ & $\begin{array}{c}\text { Decrease } \\
(n=42)\end{array}$ & $\begin{array}{c}\text { Same risk } \\
(n=42)\end{array}$ \\
\hline $\begin{array}{l}\text { Perception of risk } \\
\text { T1 }\end{array}$ & 2.0 & 2.4 & 2.7 & 2.5 \\
T2 & 1.9 & $2.7^{* *}$ & 2.4 & 2.6 \\
Change & -0.1 & 0.3 & -0.3 & 0.1 \\
\hline Estimated prevalence & & & & \\
T1 & 33.7 & 50.3 & 57.6 & 52.5 \\
T2 & $40.3^{* *}$ & $64.0^{* *}$ & 52.0 & $59.8^{*}$ \\
Change & 6.6 & 13.7 & -5.6 & 7.3 \\
\hline Influence of health and safety concerns & & & & \\
T1 & 6.6 & 5.9 & 5.0 & 5.5 \\
T2 & 6.5 & $5.5^{* *}$ & $5.5^{* *}$ & 5.7 \\
Change & -0.1 & -0.4 & 0.5 & 0.2 \\
\hline
\end{tabular}

Note. Significance levels refer to paired $t$ tests of the within-subject differences in cognition between $\mathrm{T} 1$ and $\mathrm{T} 2$.

aThis category includes only those adolescents who had driven by T2. 'Dependent variable is the mean of the two perception of vulnerability questions (range $=1-7$ ). CDependent variable is the mean of the two prevalence questions (range $=0-100$ ).

${ }^{*} p<.05 .{ }^{* *} p<.01$.

among the increasers and the smallest occurred among the decreasers $(M \mathrm{~s}=21.2$ and 6.8 , respectively). The no risk group was the only group that did not dramatically overestimate the prevalence of drinking among peers at both $\mathrm{T} 1$ and $\mathrm{T} 2$.

Smoking. Finally, in spite of the small number of participants who changed their frequency of smoking from $\mathrm{T} 1$ to $\mathrm{T} 2$, the pattern of changes in smoking-related cognitions was similar to that for drinking and reckless driving: Increases in smoking were associated with increases in risk perception $(\beta=.35, p<.01)$, increases in prevalence estimates $(\beta=.11$, $p<.05$ ), and decreases in influence of health and safety concerns $(\beta=-.20, p<.01$; see Tables 8 and 9$)$.

The ANOVAs revealed that the anticipated Time $\times$ Behavior Change Category interactions for perceptions of vulnerability and prevalence estimates were significant, $F(3,466)=$ $10.02, p<.01$, and $F(3,467)=5.46, p<.01$, respectively, and the interaction for health and safety concerns was marginal,

Table 6

Time 2 (T2) Drinking Cognitions as a Function of T2 Drinking

\begin{tabular}{|c|c|c|c|}
\hline \multirow[b]{2}{*}{ Variable } & \multicolumn{3}{|c|}{ Drinking-related cognition } \\
\hline & $\begin{array}{c}\text { Risk } \\
\text { perception }\end{array}$ & $\begin{array}{l}\text { Estimated } \\
\text { prevalence }\end{array}$ & $\begin{array}{l}\text { Infiuence } \\
\text { of health } \\
\text { and safety } \\
\text { concerns }\end{array}$ \\
\hline $\begin{array}{l}\text { T1 drinking-related cog- } \\
\text { nition (Step } 1 ; \beta \text { ) } \\
\text { T1 drinking frequency }\end{array}$ & $.43^{* *}$ & $.54^{* *}$ & $.42 * *$ \\
\hline $\begin{array}{c}\text { (Step 1; } \boldsymbol{\beta}) \\
\text { T2 drinking frequency }\end{array}$ & $-.16^{* *}$ & -.02 & -.03 \\
\hline$($ Step $2 ; \boldsymbol{\beta})$ & $.41^{* *}$ & $.23^{* *}$ & $-.29 * *$ \\
\hline $\begin{array}{l}\text { Overall } F \\
R^{2}\end{array}$ & $\begin{array}{l}81.84^{* *} \\
.34\end{array}$ & $\begin{array}{c}114.54^{* *} \\
.42\end{array}$ & $\begin{array}{l}94.11^{* *} \\
.38\end{array}$ \\
\hline$d f$ & 3,468 & 3,468 & 3,464 \\
\hline
\end{tabular}

Note. $\quad \mathrm{T} 1=$ Time 1 .

${ }^{* *} p<.01$.
$F(3,471)=2.45, p=.06$. Again, simple effects analyses across time revealed that those adolescents who increased their smoking behavior increased their perceived personal risk and prevalence estimates and reported reduced influence of concerns about health and safety $(p s<.01)$. As with the other two behaviors, the decreasers were the only group to report a decrease in their estimates of prevalence and an increase in influence of concerns about health and safety (although neither change was significant). All groups significantly overestimated the prevalence of smoking at both $\mathrm{T} 1$ and $\mathrm{T} 2$.

\section{Associations Between Changes in Cognitions}

Next, to determine whether the observed changes in risk perceptions, influence of concern about health and safety, and estimated prevalence were redundant with each other, we examined the correlations among these changes. The pattern of correlations between risk perceptions and influence of concern about health and safety was consistent across all three behaviors: Increases in risk perceptions were associated with decreases in the reported influence of health and safety concerns ( $r$ ranged from $-.15[p<.01]$ for drinking to -.10 $[p<.05]$ for reckless driving); prevalence estimates were not correlated with influence of health and safety concerns; and two of the three correlations between estimated prevalence and perceptions of vulnerability were not significant (the exception was reckless driving; $r=.11, p<.05$ ). Thus, it appears that although all three cognitions changed in the predicted directions, these changes were not redundant with each other.

\section{Changes in Subsequent Behavior as a Function of Changes in Cognitions}

To test our hypothesis that the newly adjusted thinking about health and safety and prevalence of the behavior would predict subsequent behavior changes, we conducted a series of 
Table 7

Time 1 (T1) and Time 2 (T2) Drinking Cognitions as a Function of Change Category

\begin{tabular}{lcccc}
\hline \multicolumn{1}{c}{ Cognition } & \multicolumn{4}{c}{ Change category } \\
\cline { 2 - 5 } & $\begin{array}{c}\text { No risk } \\
(n=253)\end{array}$ & $\begin{array}{c}\text { Increase } \\
(n=128)\end{array}$ & $\begin{array}{c}\text { Decrease } \\
(n=40)\end{array}$ & $\begin{array}{c}\text { Same risk } \\
(n=51)\end{array}$ \\
\hline $\begin{array}{l}\text { Perception of risk }{ }^{\mathrm{a}} \\
\text { T1 }\end{array}$ & 1.4 & 1.8 & 2.4 & 2.1 \\
T2 & $1.5^{*}$ & $2.3^{* *}$ & $1.8^{* *}$ & 2.1 \\
Change & 0.1 & 0.5 & -0.6 & 0.0 \\
\hline Estimated prevalence & & & & \\
T1 & 29.7 & 46.0 & 59.0 & 58.2 \\
T2 & $39.0^{* *}$ & $67.2^{* *}$ & $65.8^{*}$ & $67.5^{* *}$ \\
Change & 9.3 & 21.2 & 6.8 & 9.3 \\
\hline Influence of health and safety concerns & & & & \\
T1 & 6.4 & 5.5 & 4.9 & 4.7 \\
T2 & 6.3 & $4.8^{* *}$ & 4.9 & 4.3 \\
Change & -0.1 & -0.7 & 0.0 & -0.4 \\
\hline
\end{tabular}

Note. Significance levels refer to paired $t$ tests of the within-subject differences in cognition between T1 and $\mathrm{T} 2$.

${ }^{2}$ Dependent variable is the mean of the two perception of vulnerability questions (range $=1-7$ ).

bependent variable is the mean of the two prevalence questions (range $=0-100$ ).

${ }^{*} p<.05 . \quad{ }^{* *} p<.01$.

three hierarchical regression analyses predicting $\mathrm{T} 3$ reports of each risk behavior from $\mathrm{T} 2$ concern about health and safety and estimated prevalence, controlling for $\mathrm{T} 2$ behavior. In these analyses, $\mathrm{T} 2$ behavior was entered first, followed by $\mathrm{T} 2$ health and safety concern and, finally, $\mathrm{T} 2$ prevalence estimates. Table 10 presents the results of these analyses for all three behaviors. Self-reported influence of health and safety at $\mathrm{T} 2$ was a significant predictor of all three risk behaviors at $\mathrm{T} 3(p s<.01)$, such that low levels of health and safety influence were associated with subsequent increases in risk behavior. Estimated prevalence (at $\mathrm{T} 2$ ) significantly predicted changes in both drinking and smoking above and beyond the influence of health and safety ( $p s<.01)$, such that high prevalence estimates predicted increases in drinking and smoking. T2 prevalence estimates for reckless driving, however, did not predict changes in reckless driving after the influence of health and safety concerns had been removed.

Table 8

Time 2 (T2) Smoking Cognitions as a Function of T2 Smoking

\begin{tabular}{lccc}
\hline & \multicolumn{3}{c}{ Smoking-related cognition } \\
\cline { 2 - 4 } \multicolumn{1}{c}{ Variable } & $\begin{array}{c}\text { Risk } \\
\text { perception }\end{array}$ & $\begin{array}{c}\text { Estimated } \\
\text { prevalence }\end{array}$ & $\begin{array}{c}\text { Influence of } \\
\text { health and safety } \\
\text { concerns }\end{array}$ \\
\hline $\begin{array}{c}\text { T1 smoking-related cog- } \\
\text { nition (Step 1; } \beta \text { ) }\end{array}$ & $.33^{* *}$ & $.49^{* *}$ & $.40^{* *}$ \\
$\begin{array}{c}\text { T1 smoking frequency } \\
\text { (Step 1; } \beta \text { ) }\end{array}$ & .02 & .00 & -.01 \\
T2 smoking (Step 2; $\beta$ ) & $.35^{* *}$ & $.11^{*}$ & $-.20^{* *}$ \\
$\begin{array}{l}\text { Overall } F \\
R^{2} \quad\end{array}$ & $58.57^{* *}$ & $58.67^{* *}$ & $49.97^{* *}$ \\
$d f$ & .27 & .28 & .24 \\
\hline
\end{tabular}

Note. $\mathrm{T} 1=$ Time 1 .

${ }^{*} p<.05 . \quad{ }^{* *} p<.01$.
Discussion

Impact of Increased Risk Behavior on Perceptions of Vulnerability

The current study demonstrates that adolescents perceptions of vulnerability to the negative consequences of specific risk behaviors increase as their participation in these behaviors increases. Thus, these young adolescents apparently understand the relation between risk behaviors and vulnerability to negative outcomes and apply this knowledge to themselves. It appears, then, that the reason that adolescents engage in risk behavior in spite of their awareness of the potential consequences is not first-order denial of risk. Instead, these adolescents apparently engage in cognitive manipulations that allow them to deal with the inherent contradiction between their behavior and their knowledge of the danger. Two of these manipulations were identified in this study. First, those adolescents who increased their risk normalized their actions by overestimating their peers' risk behaviors to a greater extent than did other adolescents. Second, they decreased the influence health and safety concerns had on their risk behavior. Thus, they apparently avoided thinking about health and safety issues by putting such concerns out of their mind. In doing so, they engaged in what appears to be a "Scarlett O'Hara strategy" in which they say to themselves, "I won't think about this now." Furthermore, the data indicate that these cognitive manipulations were associated with subsequent increases in all three risk behaviors.

\section{The Reciprocal Relation Between Health Behavior and Health Cognitions}

The findings of this study are consistent with the traditional hypothesis that health cognitions predict subsequent health behaviors. That is, T1 concern about health and safety and prevalence estimates predicted $\mathrm{T} 2$ risk behavior after the 
Table 9

Time 1 (T1) and Time 2 (T2) Smoking Cognitions as a Function of Change Category

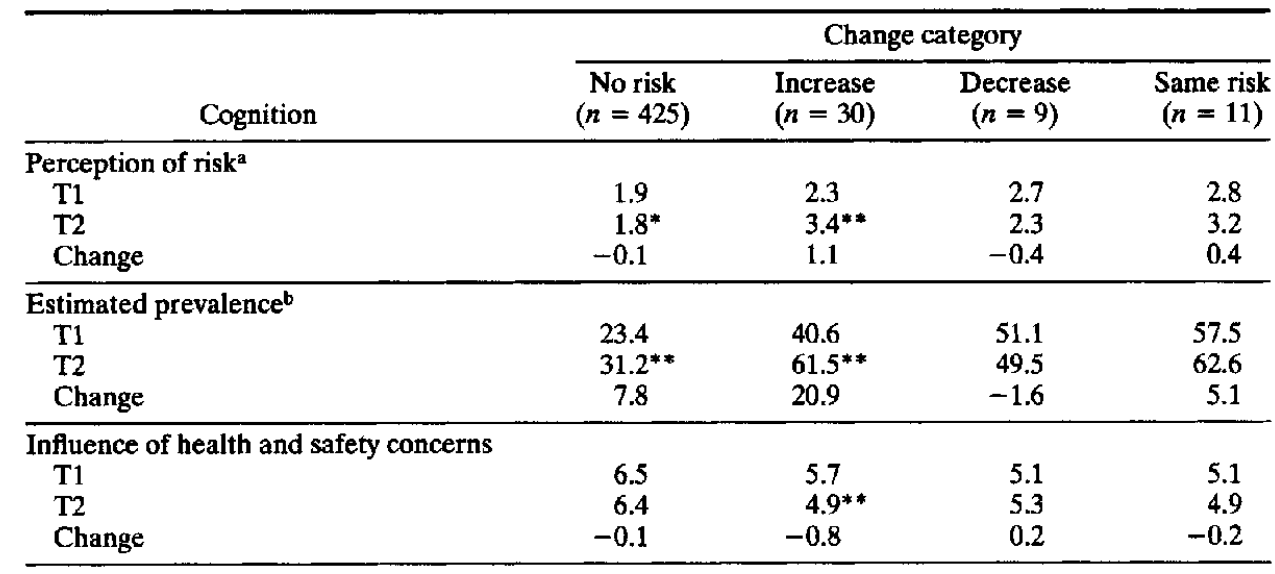

Note. Significance levels refer to paired $t$ tests of the within-subject differences in cognition between T1 and $\mathrm{T} 2$.

aDependent variable is the mean of the two perception of vulnerability questions (range $=1-7$ ). Dependent variable is the mean of the two prevalence questions (range $=0-100$ ).

${ }^{*} p<.05 . \quad * * p<.01$

influence of $\mathrm{T} 1$ risk behavior had been controlled, and changes in these cognitions between $\mathrm{T} 1$ and $\mathrm{T} 2$ predicted $\mathrm{T} 3$ risk behavior. More important, these data also provide evidence that increases in risk behavior are associated with adjustments in health cognitions. Thus, the current data suggest a more complex picture of the evolving nature of the relation between these cognitions and behaviors over time than most health behavior models do. They suggest that health cognitions affect participation in health risk behaviors and that engaging in health risk behaviors is associated with subsequent changes in health cognitions.

Whereas data collection at 12-month intervals makes it impossible to determine whether changes in cognition occur before changes in behavior, or vice versa, our conclusions regarding the impact of risk behavior on cognitions are consistent with two previous studies of the association between changes in risk behavior and a different kind of risk cognition: images of the "typical smoker." First, Gibbons, Gerrard, Lando, and McGovern (1991) demonstrated that smokers' perceptions or images of the typical smoker became signifi-

Table 10

Time 3 Risk Behaviors as a Function of Time 2

(T2) Health Cognitions

\begin{tabular}{|c|c|c|c|}
\hline Variable & $\begin{array}{c}\text { Reckless } \\
\text { driving }\end{array}$ & Drinking & Smoking \\
\hline $\begin{array}{l}\text { T2 behavior (Step } 1 ; \beta \text { ) } \\
\text { T2 influence of health and }\end{array}$ & $.38^{* *}$ & $.63^{* *}$ & $.50^{* *}$ \\
\hline$($ Step 2; $\beta)$ & $-.15^{* *}$ & $-.08^{*}$ & $-.20^{* *}$ \\
\hline $\begin{array}{l}\text { T2 estimated prevalence } \\
\text { (Step 3; } \boldsymbol{\beta})\end{array}$ & .01 & $.11^{* *}$ & $.13^{* *}$ \\
\hline $\begin{array}{l}\text { Overall } F \\
R^{2} \\
d f\end{array}$ & $\begin{array}{l}85.63^{* * *} \\
.36 \\
3,450\end{array}$ & $\begin{array}{c}115.32^{* * *} \\
.43 \\
3,451\end{array}$ & $\begin{array}{c}69.00^{* * *} \\
.31 \\
3,445\end{array}$ \\
\hline
\end{tabular}

cantly more negative over time as they tried to quit smoking. Another, more recent study demonstrated that young adults' risk prototypes (i.e., images of the typical smoker, drinker, unwed parent, and reckless driver) also changed as a function of changes in these risk behaviors (Gibbons \& Gerrard, 1995). That is, the images became more negative among those whose risk behavior declined (as was the case in the smoker study), whereas those who increased each risk behavior reported an increase in the favorability of the prototypes associated with these behaviors. The favorability of these prototypes, in turn, predicted future involvement in the behavior.

Together, the current study and the prototype studies indicate that a variety of influential cognitions shift as a result of involvement in various kinds of risk behaviors. This suggests that much of the previous research, which has relied almost exclusively on nonreciprocal models in examining the relation between cognitions and risk behavior, has perhaps addressed a set of limited questions. Specifically, previous research has demonstrated the importance of cognitions in influencing behavior by focusing on whether cognitions about risk behaviors predict who begins to smoke, drink, and so forth and who does not. Because most adolescents experiment with risk behaviors at an early age, however, it is also important to determine what pattern of reciprocal shifts in cognitions and behaviors predicts further increases in these behaviors. The current study demonstrates the relation between behaviors and cognitions over time and, in so doing, draws attention to the need to develop more complex methodologies for examining these linkages (cf. Fiske \& Taylor, 1991).

\section{Motivated Shifts?}

It is likely that adolescents whose initial experimentation leads them to the conclusion that they enjoy a specific risk behavior will begin to associate with others who engage in that 
behavior (Sheppard, Wright, \& Goodstadt, 1985), and this exposure will lead to increased prevalence estimates. Similarly, the decision to engage in a risk behavior in spite of its dangerousness is, ipso facto, evidence that one has decided to ignore or defer thoughts about the health and safety of the behavior. The correlational nature of the current study did not allow us to address the question of whether the shifts in prevalence estimates and influence of health and safety concerns we observed reflected cognitive strategies for dealing with one's increased vulnerability or were the result of unmotivated cognitive adjustments accompanying increased experience with the behaviors and increased exposure to peers who participate in the behaviors.

A recent series of studies, however, has provided evidence that these cognitive shifts may be self-serving in that they are more pronounced among people with high self-esteem. First, Smith, Gerrard, and Gibbons (in press) reported two studies designed to test the hypothesis that individuals with high self-esteem are more likely than those with low self-esteem to interpret their health behavior in a self-serving manner. In the first study we employed an experimental paradigm to demonstrate that self-esteem moderates the effect of reviewing sexual and contraceptive risk behavior on women's perceptions of vulnerability to unplanned pregnancy. In this study, reviewing risk behavior increased vulnerability estimates among women with low self-esteem, but not among women with high selfesteem. In the second study we employed a longitudinal design to demonstrate a similar moderation of the relation between naturally occurring changes in sexual behavior and changes in risk perception: Women with low self-esteem show greater increases in their vulnerability estimates after increasing their risk behavior than do those with low self-esteem. Together, these two studies demonstrated that self-esteem can mitigate the acknowledgment of the relation between behavior and vulnerability to the consequences of that behavior.

In a related study, Gibbons, McGovern, and Lando (1991) had participants of smoking cessation groups estimate their vulnerability to smoking-related diseases both before and after they attempted to quit. The responses of the participants who were successful in quitting revealed that they had increased their perceptions of the (health) benefits of quitting but had not altered their perceptions of the risks associated with smoking. The opposite pattern was reported by the relapsers, however. They did not alter their estimates of the benefits of quitting, but they significantly decreased their estimates of the health risk associated with smoking. These results raise the possibility that the relapsers were engaging in a defensive cognitive strategy designed to protect their self-esteem in the face of their failure. A more recent study by Gibbons, Eggleston, and Benthin (in press) provides support for this interpretation. This study demonstrated that decreases in perceptions of vulnerability among smokers who relapse are associated with maintenance of self-esteem. Specifically, those relapsers who did not lower their risk perceptions reported a significant drop in self-esteem, whereas those who did reduce their risk did not. In short, it appears that changes in risk behavior are associated with cognitive shifts that serve to maintain self-esteem and facilitate continued participation in the behavior. Cognitive shifts after acknowledged increases in risk behavior (like those demonstrated in the current study) may serve the same function.

\section{Limits of Increases in Perceived Vulnerability}

The narrow range in age and experience in the current sample demands caution in extrapolating from these results to older, more experienced adolescents or adults. More specifically, the pattern in these data suggests a linear relation between risk behavior and perceptions of vulnerability that is unlikely to persist as these adolescents mature. In fact, there is reason to believe that when people continue risk behaviors without experiencing negative consequences, they develop what Weinstein (1989) has labeled an "absent/exempt" perspective. Although the relation is linear in the early stages of the development of risk behaviors, it is likely that instead of resulting in ever-increasing perceptions of vulnerability, these perceptions will eventually at least stabilize and perhaps decrease, leading the individual to believe that "if it hasn't happened to me so far, it isn't likely to happen to me at all." This decline in the association between perceptions of vulnerability and risk behavior may, once again, eventually "allow" or facilitate future increases in risk.

\section{Implications for Intervention}

The current data point to a need for further research on the combination of cognitive shifts promoting increases in risk behaviors. More specifically, given that most adolescents at least experiment with a variety of risk behaviors at a very early age, it is important that future research examine specific patterns of cognitive shifts that promote the progression from initiation of and experimentation with such behaviors to increased involvement. Two groups of researchers have recently proposed interventions compatible with the current findings. Graham, Marks, and Hansen (1991) have argued that alcohol and drug educational programs should be designed to include efforts to correct misperceptions about the prevalencespecifically overestimations - of use among peers (cf. Graham, Collins, Wugalter, Chung, \& Hansen, 1991). Similarly, Prentice and Miller (1993) have demonstrated that college students who mistakenly believe that their negative attitudes about excessive drinking are not shared by others are motivated to conform to their (mis)perception that overindulgence is both normative and expected. Thus, these authors suggest that encouraging college students to share private attitudes about drinking, thereby exposing this pluralistic ignorance, will promote social changes by demonstrating that negative attitudes about excessive drinking are not deviant. Although the current data are consistent with both of these proposals, the finding that both misperceptions of prevalence and influence of health and safety concerns are altered by engaging in the risk behavior suggests that interventions designed to reduce pluralistic ignorance and overestimation of prevalence will be most effective if directed at young people before they begin to experiment with the risk behaviors, that is, before the process of engaging in the behavior has affected their cognitions about the prevalence and riskiness of the behavior. 


\section{References}

Brown, B. B., Clasen, D. N., \& Eicher, S. A. (1986). Perceptions of peer pressure, peer conformity dispositions, and self-reported behavior among adolescents. Developmental Psychology, 22, 521-530.

Centers for Disease Control (1992). Recent trends in adolescent smoking, smoking-uptake correlates, and expectations about the future. Advance Data, 221.

Centers for Disease Control. (1993). Teenage pregnancy and birth rates-United States 1990. Morbidity and Mortality Weekly Report, $42,39$.

Cohn, L. D., Macfarlane, S., Yanez, C., \& Imai, W. K. (1995). Risk-perceptions: Differences between adolescents and adults. Health Psychology, 14, 217-222.

Collins, L. M., Sussman, S., Rauch, J. M., Dent, C. W., Johnson, C. A., Hansen, W. B., \& Flay, B. R. (1987). Psychosocial predictors of young adolescent cigarette smoking: A sixteen-month, three-wave longitudinal study. Journal of Applied Social Psychology, 17, 554-573.

Croyle, R. T. (1990). Biased appraisal of high blood pressure. Preventive Medicine, 19, 40-44.

Croyle, R. T., \& Sande, G. N. (1988). Denial and confirmatory search: Paradoxical consequences of medical diagnosis. Joumal of Applied Social Psychology, 18, 473-490.

Ditto, P. H., Jemmott, J. B., \& Darley, J. M. (1988). Appraising the threat of illness: A mental representational approach. Health Psychology, 7, 183-201.

Eiser, C., Eiser, J. R., \& Lang, J. (1989). Adolescent beliefs about AIDS prevention. Psychology and Health, 3, 287-296.

Festinger, L. A. (1957). A theory of cognitive dissonance. Evanston, IL: Row, Peterson.

Finn, P., \& Bragg, B. W. (1986). Perception of the risk of an accident by young and older drivers. Accident Analysis and Prevention, 18, 289-298.

Finn, P., \& Brown, J. (1981). Risks entailed in teenage intoxication as perceived by junior and senior high school students. Joumal of Youth and Adolescence, 10, 298.

Fiske, S. T., \& Taylor, S. E. (1991). Social cognition. New York: Random House.

Gerrard, M., Gibbons, F. X., \& Bushman, B. J. (1996). The relation between perceived vulnerability to HIV and precautionary sexual behavior. Psychological Bulletin, 119, 390-409.

Gerrard, M., Gibbons, F. X., \& Warner, T. D. (1991). Effects of reviewing risk-relevant behaviors on perceived vulnerability of women Marines. Health Psychology, 10, 173-179.

Gerrard, M., Gibbons, F. X., Warner, T. D., \& Smith, G. E. (1993). Perceived vulnerability to AIDS and AIDS preventive behavior: $A$ critical review of the evidence. In J. Pryor \& G. Reeder (Eds.), The social psychology of HIV infection (pp. 59-84). Hillsdale, NJ: Erlbaum.

Gerrard, M., \& Luus, C. E. (1995). Judgments of vulnerability to pregnancy: The role of risk factors and individual differences. Personality and Social Psychology Bulletin, 21, 158-169.

Gibbons, F. X., Eggleston, T., \& Benthin, A. C. (in press). Smoking relapse and risk perception: Influence of, and influence on selfesteem. Journal of Personality and Social Psychology.

Gibbons, F. X., \& Gerrard, M. (1995). Predicting young adults' health risk behavior. Joumal of Personality and Social Psychology, 69, 505-517.

Gibbons, F. X., Gerrard, M., \& Boney-McCoy, S. (1995). Prototype perception predicts (lack of) pregnancy prevention. Personality and Social Psychology Bulletin, 21, 85-93.

Gibbons, F. X., Gerrard, M., Lando, H. A., \& McGovern, P. G. (1991). Social comparison and smoking cessation: The role of the "typical smoker." Journal of Experimental Social Psychology, 27, 239-258.

Gibbons, F. X., Helweg-Larsen, M., \& Gerrard, M. (1995). Prevalence estimates and adolescent risk behavior: Cross-cultural differences in social influence. Joumal of Applied Psychology, 80, 107-121.

Gibbons, F. X., McGovern, P. G., \& Lando, H. A. (1991). Relapse and risk perception among members of a smoking cessation clinic. Health Psychology, 10, 42-45.

Goethals, G. R., Messick, D. M., \& Allison, S. T. (1991). The uniqueness bias: Studies of constructive social comparison. In J. Suls \& T. A. Wills (Eds.), Social comparison: Contemporary theory and research (pp. 149-176). Hillsdale, NJ: Erlbaum.

Graham, J. W., Collins, L. M., Wugalter, S. E., Chung, N. K., \& Hansen, W. B. (1991). Modeling transitions in latent stagesequential processes: A substance use prevention example. Journal of Consulting and Clinical Psychology, 59, 48-57.

Graham, J. W., Marks, G., \& Hansen, W. B. (1991). Social influence processes affecting adolescent substance use. Joumal of Applied Psychology, 76, 291-298.

Harrison, J. A., Mullen, P. D., \& Green, L. W. (1992). A meta-analysis of studies of the health belief model with adults. Health Education Research 7, 107-116.

Janis, I. L. (1958). Psychological stress. New York: Wiley.

Janus, S., \& Janus, C. (1993). Janus report on sexual behavior. New York: Wiley.

Janz, N. K., \& Becker, M. H. (1984). The health belief model: A decade later. Health Education Quarterty, 11, 1-47.

Kandel, D. (1980). Drug and drinking behavior among youth. Annual Review of Sociology, 6, 235-285.

Lawton, M. P., \& Goldman, A. E. (1961). Cigarette smoking and attitude toward the etiology of lung cancer. Joumal of Social Psychology, 54, 235-248.

Lazarus, R. S. (1983). The costs and benefits of denial. In S. Breznitz (Ed.), The denial of stress (pp. 1-30). New York: International Universities Press.

Leventhal, H., Glynn, K., \& Fleming, R. (1987). Is the smoking decision an 'informed choice'?: The effect of smoking risk factors on smoking beliefs. Joumal of the American Medical Association, 257, 3373-3376.

Marks, G., Graham, J. W., \& Hansen, W. B. (1992). Social projection and social conformity in adolescent alcohol use: A longitudinal analysis. Personality and Social Psychology Bulletin, 18, 96-101.

Pervin, L. A., \& Yatko, R. J. (1965). Cigarette smoking and alternative methods of reducing dissonance. Joumal of Personality and Social Psychology, 2, 30-36.

Prentice, D. A., \& Miller, D. T. (1993). Pluralistic ignorance and alcohol use on campus: Some consequences of misperceiving the social norm. Journal of Personality and Social Psychology, 64, 243 256.

Public Health Service. (1993). Prevention: Federal programs and progress. '91/'92. Washington, DC: Office of Disease Prevention.

Roscoe, B., \& Kruger, T. L. (1990). Late adolescents' knowledge and its influence on sexual behavior. Adolescence, 25, 38-48.

Ross, L., Greene, D., \& House, P. (1977). The false consensus phenomenon: An attributional bias in self-perception and socialperception processes. Journal of Experimental Social Psychology, 13, 279-301.

Rotheram-Borres, M. L., \& Koopman, C. (1991). Sexual risk behaviors, AIDS knowledge, and beliefs about AIDS among runaways. American Joumal of Public Health, 81, 206-208.

Rothman, A. J., Klein, W. M., \& Weinstein, N. D. (in press). Absolute and relative biases in estimation of personal risk. Joumal of Applied Social Psychology.

Sheppard, M. A., Wright, D., \& Goodstadt, M. S. (1985). Peer pressure and drug use-Exploding the myth. Adolescence, 20, 949-958.

Sherman, S. J., Presson, C. C., Chassin, L., Corty, E., \& Olshansky, R. (1983). Mechanisms underlying the false consensus effect: The 
special role of threats to the self. Personality and Social Psychology Bulletin, 10, 127-138.

Smith, G. E., Gerrard, M., \& Gibbons, F. X. (in press). Self-esteem and the relation between risk behavior and perceived vulnerability to unplanned pregnancy in college women. Health Psychology.

Snyder, M. L., \& Wicklund, R. A. (1981). Attribute ambiguity. In J. H. Harvey, W. Ickes, \& R. F. Kidd (Eds.), New directions in attribution research (Vol. 3, pp. 197-221). Hillsdale, NJ: Erlbaum.

Stacy, A. W., Widaman, K. F., Hays, R., \& DiMatteo, M. R. (1985). Validity of self-reports of alcohol and other drug use: A multitraitmultimethod assessment. Joumal of Personality and Social Psychology, 49, 219-232.

Suls, J., Wan, C. K., \& Sanders, G. S. (1988). False consensus and false uniqueness in estimating the prevalence of health-protective behaviors. Joumal of Applied Social Psychology, 18, 66-79.

Sussman, S., Dent, C. W., Mestel-Rauch, J., Johnson, C. A., Hansen, W. B., \& Flay, B. R. (1988). Adolescent nonsmokers, triers, and regular smokers' estimates of cigarette smoking prevalence: When overestimations occur and by whom? Joumal of Applied Social Psychology, 18, 537-551.

U.S. Department of Health and Human Services. (1990). Healthy people 2000: National health promotion and disease prevention objectives (DHHS Publication No. PHS 91-50212). Washington, DC: Author.

Weinstein, N. D. (1989). Effects of personal experience on selfprotective behavior. Psychological Bulletin, 105, 31-50.

Weinstein, N. D., \& Nicolich, M. M. (1993). Correct and incorrect interpretations of correlations between risk perceptions and risk behaviors. Health Psychology, 12, 235-245.

Weinstein, N. D., Rothman, A. J., \& Nicolich, M. M. (1995). Use of correlational data to examine the effects of risk perceptions on precautionary behavior. Manuscript submitted for publication.

Weisman, A. D. (1972). On dying and denying. New York: Behavioral Publications.

\title{
Call for Nominations
}

The Publications and Communications Board has opened nominations for the editorship of Developmental Psychology for the years 1999-2004. Carolyn Zahn-Waxler, PhD, is the incumbent editor.

Candidates should be members of APA and should be available to start receiving manuscripts in early 1998 to prepare for issues published in 1999. Please note that the P\&C Board encourages participation by members of underrepresented groups in the publication process and would particularly welcome such nominees. Self nominations are also encouraged.

To nominate candidates, prepare a statement of one page or less in support of each candidate and send to

\author{
Janet Shibley Hyde, PhD, Search Committee Chair \\ c/o Lee Cron, P\&C Board Search Liaison \\ American Psychological Association \\ 750 First Street, NE, Room 2004 \\ Washington, DC 20002-4242
}

Members of the search committee are Bennett Bertenthal, $\mathrm{PhD}$; Susan Crockenberg, $\mathrm{PhD}$; Margaret Spencer, $\mathrm{PhD}$; and Esther Thelen, $\mathrm{PhD}$.

First review of nominations will begin December 9, 1996. 